\title{
Research on the Technological Innovation System Construction of Hi-tech Enterprises in Xi'an
}

\author{
Wenjing Chu \\ Xi'an Peihua University, Xi'an, Shanxi Province, 710125
}

Keywords: Technological Innovation System, Construction, Hi-tech Enterprises, Xi'an

\begin{abstract}
The economic development of China has shown a new normal and the mode of economic development has entered into a period of restructuring and adjustment. The demand for science and technology in economic development has been constantly increasing, and the development of high-tech industries has shown an upward trend. As one of the six high-tech industry development bases in China, Xi'an, with its own industrial advantages, has been in a growing state of high-tech industries. However, with the objective reality of the transformation of China's economic development mode, high-tech industries in Xi'an also face the dual challenges from domestic and foreign markets and the task of industrial restructuring. Based on the research ideas of descriptive research, analytical research and countermeasure research, this paper studies the construction of innovation system of high-tech enterprises in Xi'an.
\end{abstract}

\section{Introduction}

Since the late 1980s, with the approval of the Central Government of our country and with the organization and implementation of the Ministry of Science and Technology, our country has started to implement the development plan called "Torch Plan" aimed at the development of high-tech industries. The plan marks the development of China's high-tech industry has entered a new stage. Since then, most of the provinces in our country started to develop high-tech industries and qualified areas in their own province according to the actual conditions and set up hi-tech industrial development zones through examination and approval by the state as an important organization for the development of high-tech industries. In 1991, in accordance with development needs, Xi'an set up a state-level high-tech industrial development zone in Xi'an, marking a new phase in the development of high-tech industries in Xi'an and even the northwest [1].

It clearly puts forward the "innovation-driven development strategy." Based on the spirit of the Central Government and the actual situation of Shaanxi's development, Shaanxi Province proposed the strategic plan for building "three of Shaanxi's". In 2010, Xi'an proposed "Greater Xi'an" strategy based on its own development and long-term development plan. It clearly stated in its strategic development goal that Xi'an will be the future major national high-tech industrial base. Both from the country's overall development requirements, the development direction of the region and the city's development prospects require that Xi'an vigorously develop high-tech industries. The added value of hi-tech industry in Xi'an reached 10.046 billion yuan in 2005, accounting for $7.9 \%$ of the gross domestic product (GDP) of Xi'an in the same year. In 2012, it was 51.082 billion yuan, accounting for $11.69 \%$ of the total GDP of Xi'an \%. During the past 7 years, the proportion of the added value of high and new technology industries in Xi'an accounting for the total amount of Xi'an's GDP has been on the rise and has been rising year by year, thus becoming an important driving force for the economic development of this municipality [2]. High-tech development momentum is good, but in the development process, such as the internal layout of the industry is not rational, the investment and financing system is not perfect, personnel training deficiencies, the level of low-level introduction of technology and these factors have hindered the high-tech industry in Xi'an longterm development. 


\section{The Definition of High-tech Industries}

There are differences in the definition of high-tech industries in different countries. Japan believes that high-tech industries are a group of related industries that are technology intensive, have a short reform cycle, save resources and have a certain expected market. Some Western countries use quantitative methods to define high-tech industries. For example, the United States defines the industry as having more than $10 \%$ of the total added value of R \& D funds (research and development funding) or more than $10 \%$ of the total number of employees engaged in scientific and technological activities for high-tech industries. The OECD definition of high-tech industries is also constantly changing, fully demonstrating that high-tech industries are a dynamic concept. Canadian scholars define it from two perspectives, that is, high-tech industry as a special industrial production sector must rely on the technical quality of labor force and research and development funding to reflect; design high-tech industry as pre-production design and technology adjustment, with research and manufacturing engineers and technicians in the number of proportion to reflect. Domestic scholars generally believe that high-tech industries are engaged in high-tech research, development, promotion, making the process of commercial enterprises in the general term, characterized by a large number of investments in scientific research during the commercialization process, a large investment in scientific research, with Super industrial relations and radiation.

\section{The Environment to Build High-tech Enterprise Technology Innovation System of Xi'an}

\subsection{Political Environment}

Xi'an City, in carrying out the "stable and steady progress" of the Central Government and Shaanxi Province, responded to the overall downward pressure on the economy and brought new impetus to the high-tech industry in Xi'an. Under the guidance of the overall tone, the ability of high-tech industries to resist external risks will be enhanced and will play a supporting role in the high-tech industries. With policy as the basis, all enterprise departments in the high-tech industries are constantly strengthening their ability to withstand risks so that they can participate in market competition to the maximum extent and try to break through the existing markets, open new markets and further develop the entire industry.

The "stable" keynote ensures that the high and new technology industries in Xi'an still have the existing policy support and government support to ensure the smooth progress of the enterprises and enjoy the original inclination in production, technology and taxation. The keynote of "progressing into the country" necessarily requires the government to make policy adjustments that are more conducive to industrial development and promote the economy. For the city of Xi'an, a city of science and technology, under the guidance of the new policy, it has the opportunity to promote industrial development. In addition, the "steady progress" also brought changes in the ideology and concepts for the development of the industry in this sub-district and provided a steady development tone for the newly launched and emerging industries [3].

\subsection{Economic Environment}

The momentum of external investment in Xi'an has been in an overall growth trend since the beginning of this century. The external investment environment has a direct impact on the attractiveness of foreign capital for the region. Since 2000, affected by the national strategy of developing the western region and the development of the central and western regions In the past five years, the number of foreign direct investment projects approved by Xi'an City, the amount of foreign direct investment contractual use and the actual amount of direct foreign investment by foreign investors in Xi'an have been on the rise. Among them, the number of projects approved for foreign direct investment increased from 82 in 2010 to 103 in 2014, of which the growth rate in 2013 reached $74.71 \%$, an increase of $86.83 \%$ over 2012 .

However, due to the world economic recession, the downward pressure on the economy brought by the "three-period" superposition increased. Xi'an City, focusing on the direction of investment in 
foreign-funded projects, from the energy, chemical and other traditional industries into the direction of new energy sources, photovoltaic industry, investment in the relevant policies, the preferential treatment also have varying degrees of reduction for foreign-funded enterprises Scale and conditions of the company are stricter and qualification requirements are further raised, thus affecting foreign investment projects and resulting in the approval of the growth surge in growth rate. The actual growth in 2014 was $-32.4 \%$, down by 106.95 percentage points from 2013.

\subsection{Social Environment}

The overall stability and harmony of the social environment are very important for the development of any industry. Because of their high-tech characteristics, high-tech industries decide that they need diversified resources during the development process and that integration requires the cooperation of various production departments, especially the technical and resource support of industrial production departments. This requires the community to provide a relatively stable production environment for the development of high-tech industries to provide protection. Xi'an has a relatively stable industrial production environment in the development of hi-tech industries [4]. The total profit of industrial enterprises above designated size in Xi'an is basically the same as the growth of main income, which is in a relatively steady growth. However, the fluctuation in the growth rate fluctuates greatly in Xi'an, which also shows that the industrial development in Xi'an is affected by the overall economic environment in the country and thus the development of the industry has brought no small impact.

\subsection{Technical Environment}

The more high-tech industries with high industrial added value, the demand for talent is even more dependent on the formation of a strong talent support for any industry are extremely important, high-tech industries as one of the modern science and technology research and development center, the quantity and quality of human resources play a key role in the industry.

Xi'an has obvious advantages both in terms of hardware environment and software and environmental science and technology resources. Xi'an ranks among the highest in the number of universities and research institutes in China. By 2011, it now has 61 institutions of higher learning, including 6 directly-affiliated institutions at the ministry level, which is at the leading level in China. In recent 5 years, the average number of college graduates is nearly 200,000, showing an upward trend year by year. Xi'an has 625 scientific and technological research institutions, ranking first in the northwest region; it is also one of the six high-tech industrial bases in the country. It can be seen that there is sufficient reserves of potential scientific and technological personnel resources, both in terms of the quantity and quality of personnel training. The huge resources of science and technology talents provide the possibility for the improvement and upgrading of innovation ability and R \& D capability of high-tech industries in Xi'an.

\section{Xi'an High-tech Enterprise Technology Innovation System}

Establish a youth science and technology personnel training program. The reserve of scientific and technological human resources is an essential resource for industrial transformation of production mode and industrial upgrading. It is an important factor for the sustainable development of the industry and an important item for measuring the level of industrial development. Scientific and technological personnel training are not accomplished in one go, need long-term investment. Although the process of talent cultivation has a long cycle, the benefits brought by talents once they are produced by the enterprises are also extremely impressive.

Since the resumption of college entrance examination, the national personnel training system has rejuvenated. Although Xi'an is located in the northwestern region, the number and quality of colleges and universities both belong to the forefront in the country. There are many kinds of scientific research institutes, with large numbers and large supply of talents. Xi'an has a natural talent advantage, which requires that Xi'an should seize this advantage, so that huge talents can be transformed into scientific and technological talents that meet the needs of industrial development. 
High-tech enterprises in Xi'an should set up a program of training young talents to provide theoretical opportunities for more young scientists and technicians.

Improve corporate R \& D incentive mechanism Talent not only needs training, but also need to manage. How to improve the scientific research enthusiasm of scientific and technological personnel, stimulate the scientific research potential of scientific and technological talents, and make science and technology talents richer and have the enthusiasm of scientific and technological innovation are the important aspects to enhance the industrial innovation ability.

Innovation enthusiasm to improve scientific and technological personnel to rely on encouragement, but more for industrial development should focus on incentives for talent. As long as the ideas of personnel for scientific research continue to increase, the efficiency and quality of research and development of science and technology can be improved. Affected by the traditional economic system in our country, both the industrial workers and the scientific researchers in the enterprises are restrained by the system and cannot exert huge productive force under the framework of a planned economy. The way of income distribution in our country has undergone tremendous changes, which has greatly enhanced the creativity of human resources and the productivity of human resources. Therefore, as a high-tech enterprise, it is also necessary to flexibly use various forms of distribution so as to stimulate scientific and technical personnel and further promote their enthusiasm for scientific research [5].

Give priority to supporting the development of special industries. "The trains run fast, thanks to the front belts", industrial development should focus on overall promotion, but also pay attention to individual outstanding. High-tech industry in Xi'an as of 2011, 3000, there are advantages in the number of enterprises, the proportion of the number of leading enterprises can be low, fully reflect the core competitiveness of industrial development is still not enough. To ensure the lasting vitality of high-tech industries in Xi'an, we must give full play to the benchmarking role of large-scale science and technology enterprises in technological innovation activities, encourage enterprises to expand their research and development centers, organize and lead independent innovation activities in the latest scientific and technological forward positions, and build a world-class enterprise. On this basis, small and medium-sized scientific and technological enterprises will be driven to attach themselves to the industrial chain so that the achievements in independent innovation will continue to emerge. This will maximize the overall effectiveness of high-tech industries by bringing them to a point.

Create a safe investment and financing service environment. Attracting foreign investment has become one of the necessary means for the development of modern industry. Any enterprise that wants to grow rapidly cannot grow independently from the external environment. Industry investment can get rich financial support and advanced technical support. Since the development of high-tech industry in Xi'an so far, foreign funds have provided great help to the development of industrial belt. Xi'an City, the actual results brought about by the introduction of investment is very obvious, strengthening the overall economic strength of Xi'an; hatched a number of high-tech enterprises with excellent technology; many powerful international companies stationed in Xi'an, so that the high-tech development zone visibility greatly improved ; Optimizing the industrial structure of high-tech industries in Xi'an, enriching the sources of capital and technology for industrial development and overall optimizing and upgrading the industries. However, we should also clearly see the shortcomings in the investment promotion process. The competition from the outside is fiercer and the capital grab is inevitable. The convergence of types of industrial production, leading to increasing competition for internal funds, the overall quality of investment is not high.

\section{Conclusions}

The 21st century is the century for science and technology innovation. High and new technology industries take science and technology innovation as the fundamental driving force for development. Their development prospects will depend more on science and technology innovation. In the course of deepening the concept of innovation and development, relying on innovation-driven development strategies to promote the development of high-tech industries is an opportunity and a challenge to 
the entire industry.

\section{Acknowledgements}

Fund Project: Xi'an Social Science Planning Fund Peihua special subject, subject code: 17PH15.

\section{References}

[1] Cao Wenhu. Research on Innovation Efficiency of Hi-tech Industry Based on DEA - A Case Study of Western China [J]. 62-67.

[2] Lu Changli, Wu Xiongying. Research on R \& D Efficiency of High-tech Industry in East Coast of China [J]. Productivity Research. 2013 (09) 42-45.

[3] Lin Min, Wang Yi, Wu Guisheng. Study on the Development Mode of Strategic Emerging Industry in Western Region [J]. Science and Technology Progress and Policy. 2013 (17) 50-78.

[4] Peng Jianguo, Guo Peng, Yu Mingjie. Research on innovation efficiency of high-tech industry based on factor analysis model [J]. Machinery Design and Manufacturing Engineering. 2013(08) 189-192.

[5] Li Juan, Zhang Yajiao, Liu Hu. Research on Co-integration Relationship between Intellectual Property and Development of Five Leading Industries - A Case Study of Five Leading Industries in Xi'an, New and High Technology Industry [J]. Electronic Testing. 2013 (12) 452-467. 